even the discipline of a hospital and the most rigorous diet had been unable to break the spell.

CASE 1.-Albert S., aged 15, was admitted into the Radcliffe In. firmary under my care on November 2nd, 1871. He was reported to have vomited all his food since the beginning of July. Before this he had been weakly and disinclined to work, refusing to follow up the trade to which his father had apprenticed him. He had not left his bed for three months, but had been nursed and anxiously watched by a foolishly kind mother, who had herself once been insane, and was at all times eccentric. He had not spoken a word for many weeks. All kinds of medical treatment had been tried in vain. His face was pale; his body and limbs were much emaciated; his eyelids, mouth and chin in a state of constant twitching. When spoken to, he burst into tears. No sign of disease could be detected in any part of the body; no pain or tenderness in the abdomen. The nurse stated that he had vomited everything taken since admission, twenty-four hours previously. The romited matters consisted of unchanged food. He was ordered to take one tablespoonful of milk and lime-water every half hour, and to suck ice; no medicine was given. On the third day, I found that he had vomited each spoonful of milk as soon as it was taken. The nurse had observed that, as soon as the milk was swallowed, he raised himself into a half-sitting posture and began to " heave." I ordered her to prevent him from doing this, to sit by his side and keep him flat on his back after each dose of milk. On the fourth day, he had kept down the greater part of the milk. On the fifth day, he had kept down all the milk and some minced mutton. On the eighth day he was eating mutton and potatoes, and sitting up in bed. He was finally discharged on January 22nd, 1872, fat and cheerful, having gained while in the Infirmary more than a stone in weight. $\mathrm{He}$ is at the present time strong and well.

CASE II was related to me by my friend Dr. Gray, who kindly allows me to insert it here. I give it in his own words. "The patient was a schoolboy, aged 13 or 14 , pale and thin, much spoiled at home, an only son, of very feeble power of will. His father had died of drinking. He had had chronic vomiting soon after food for some weeks, when I first saw him. With this there had been troublesome constipation, and, for a few days, slight painless jaundice. I continued to attend him at school for some time, trying every remedy I could think of, without avail. From the persistence of the vomiting, long after the jaundice and constipation had yielded, and in absence of any tenderness at the epigastrium, or complaint of pain after food, I suspected that the vomiting, however caused in the first instance, was kept up by habit; and, as I knew the boy's mother well, I got her to let him live with me in my house for a few days. The first day, after dinner, he said he must leave the table to be sick. I made him sit still where he was, brought a basin within reach, and kept him engaged in conversation to divert his mind. The end was, that he did not vomit, or even retch. After tea I did the same, with the same result. After a few days on this tack, without any medicine, or any restriction in diet, he had quite got over his habit of vomiting, and never again had any trouble of the kind."

CASE III.-Kate M., aged 14, was admitted into the Radcliffe Infirmary, under my care, on January 16th, 1873. She was reported to have first begun to vomit her food, directly after it was taken, eighteen months ago, and to have continued this habit for a twelvemonth. The vomiting had then stopped for three months, but had begun again three months previously, and gone on uninterruptedly till the date of her admission. She had never suffered any pain, nor could the sickness be ascribed to any cause. She had never menstruated. All kinds of medical treatment had been tried in vain. She was pale and thin had a quick, sharp manner; was evidently much interested in the examination of her case, and had plenty to say about her state and symptoms. No kind of disease could be detected in any part of her body. The nurse stated that the girl had vomited everything that she had taken since admission; and added, on my inquiring how the act of vomiting was performed, that, directly after each meal, she ran to the water-closet and began to retch till the stomach emptied itself. Some vomited matters, which I saw, consisted of unchanged food. I directed the nurse to place her on her back, and keep her in that posture, for half an hour after each meal. The regular hospital diet, with meat and vegetables, was ordered, but no medicine was given. From this time forth the vomiting stopped. The treatment by posture was continued for ten days, after which time the girl was allowed to do as she pleased after meals, but she showed no inclination to return to her old habit, and was discharged cured on February $5^{\text {th. }}$

In all these cases, the habit was broken by first noticing the way in which the child set about the act of vomiting, and then suddenly interrupting it in its performance.

\section{THE SANITARY STATE OF ROME.}

\section{By LAUCHLAN AITKEN, M.D., Rome。}

So many articles had appeared, both in professional journals and in the daily and weekly newspapers and reviews, on the unhealthy state of Rome during the last twelve months, that in the autumn of last year I began to make the necessary inquiries and to endeavour to ascertain the true condition of the city. This I found by no means an easy matter, partly owing to the fact that the proper elements for a fair comparison of the sanitary state of the city in the past year with those which had preceded it were nearly if not altogether wanting, and partly because a very large proportion of the deaths in Rome occur in the hospitals ; and it is now, and will be for some time, impossible to obtain exact data for the year from the directors of those institutions. Finally, however, through the courtesy of the Cavaliere Silvagni, the head of the statistical department at the Capitol, I was furnished with all the information the office had obtained on the health of Rome in 1872 ; and the results embodied in this article have been almost entirely gathered from the various and excellent reports issued by the Cav. Silvagni throughout the year-reports which the author, with the greatest kindness, has allowed me to use at my discretion. I was also favoured by Dr. Bianchi with some excerpts from the books of the largest medical hospital in Rome-the Santo Spirito. These various reports, with the oral information obtained from many of the medical men in Rome, enable me to present a more accurate and detailed account of the sanitary condition of the city, as well as of the reasons for its high death-rate, than I at one time thought it would be possible to do.

The establishment of a registration office at the Capitol in Rome under the Italian government, only dates from the Ist of February, 187I; and as yet, of course, it is unable to supply the materials for a satisfactory comparison of the present state of the city with that of former years, even if such comparison were possible; but, as the Papal authorities were accustomed to furnish the returns from one Easter to the other, there is thus introduced an element of confusion into the reports which it will be most difficult to set aside. In addition to this, as the only official census made by order of Pope Pius IX, was in the year 1853, when the population of Rome and the Agro Romano* was found to be 177,014 , it is evident that the estimates of the inhabitants during the decennium from 1860 to 1870 must have been to a great extent conjectural, and consequently untrustworthy for statistical purposes. This is more apparent, if we bear in mind that the first census undertaken by the Italian government on the last day of 1871 and the first of 1872 proved the population to be 244,484 , showing an increase of 67,470 in the nineteen preceding years. Another curious fact goes far to prove the unsatisfactory nature of the bases for the returns from 1860 to 1870 . In the year 1860 , when the population was estimated at 184,000 , the births numbered 5,907; while in 1870, when the population had increased to 226,000 , the births were only 5,755 , or actually fewer in number than in 1860 , in spite of the great increase of inhabitants. Nor was this falling off in the births due apparently to any disturbing political element, as the nine intervening years show similar strange fluctuations, though the estimated population gives an increase from year to year; in none of them were so many children born as in 1860.

In turning to the careful and extended report which Signor Salvagni has issued since the establishment of the statistical office in the beginning of $187 \mathrm{I}$ and to the last census returns, it becomes obvious that the basis for the results arrived at may be regarded as fairly accurate. From them, it appears that the death-rate of the city has become materially higher within the last three years; for, while in 1870 the proportion of deaths was 24.8 to 1,000 inhabitants, in 1871 it had risen to 31 . I per $1, \infty 00$, and in 1872 to 37.4 , this last number being very alarming, and greatly in excess of the mean annual mortality of all the larger capitals of Europe. On examining the weekly tables furnished by the registrar more closely, we find that this mortality was unequally distributed over the different quarters of the year. For the first quarter it is impossible to furnish an accurate statement, owing to the fact that in the returns of the first four weeks are included many deaths not belonging to the community; for the second (April, May, June), the mortality was 339 per 1,000 living; for the third (July, August, September), 39.8 per 1,000 ; and in the last quarter it had again diminished, being 35.01 per I,, 00 inhabitants.

In estimating the mortality of the year, I have thought myself justified in deducting the still-births and those deaths which occurred in the hospitals or city but did not belong to the community. Of the former

* Rome and the Agro Romano embrace an extent of country of about 815 square miles. 
there were as many as 322, while the aggregate of individuals dying in Rome, but belonging to other parts of Italy and to foreign countries, was 836 for eleven months of the year. *After the subtraction of those deaths, the total mortality for the year was 9,144 , or 37.4 per 1,000 living. The high death-rate among those not belonging to the community requires some explanation, and seems partly due to the fact of Rome having been overcrowded with the poorest of the labouring classes from all parts of the kingdom, who anticipated obtaining employment on the numerous public works which have been begun since the city came into possession of the Italians, and who, on account of the greatly enhanced prices of food and lodging, have been most wretchedly fed, and have been obliged to live in underground cellars without light or air in the colder season, while in the hotter months their sole sleeping quarters were too often the porticoes of the churches and public buildings. Among those unfortunate people the mortality has been appalling, and, as most of them came from parts of Italy where there was no ague, it has been greatly owing to pernicious intermittent fever. In addition, it is probable that the hospitals of Rome have attracted to them the invalids from a wider district of country than they used to do, as almost all the deaths of those not belonging to the community took place in the hospitals, only 90 out of 836 having died elsewhere in the city; figures which by themselves go far to prove that foreign residents and visitors suffered but little from the prevalent unhealthiness of the year. During the four months, July, August, September, and October, there were admitted I1,000 patients into one hospital, the Santo Spirito, or nearly as many as are usually received throughout the whole year. In the medical hospitals, with the exception of one or two wards used for clinical purposes, there is no part of the various buildings which even partially answers to the requirements of modern hospital construction, and with any great influx of patients the overcrowding must prove most deadly. The surgical hospitals are better constructed, but they, too, are overflowing with patients, and, indeed, rather more than one death out of every three-and-a-half deaths in 1872 took place in the hospitals.

In endeavouring to explain the high death-rate of the past twelve months in Rome, we find that in the first quarter the increased mortality was greatly owing to an epidemic of small-pox which, beginning in the October of $187 \mathrm{I}$, gradually increased in severity until about the end of the third week in January, 1872, when it attained its maximum. Between the Ioth of October, $187 \mathrm{r}$, and the 4 th of February, 1872, the epidemic caused no fewer than 544 deaths, 209 of which are included in the death returns of 1872 . From the middle of February the epidemic began to abate, and by the middle of August the deaths from this cause had fallen to an average of 7 per week. Still, the slaughter caused by small-pox has been truly startling, 737 persons having lost their lives in one year from this the most preventable of zymotic diseases. That a large number of those deaths must be ascribed to the want of vaccination, or to its careless and inefficient performance, may be concluded from the returns, which prove that 67.6 per cent. of all the deaths from small-pox were those of children under five years of age, many of which a compulsory Vaccination Act would have prevented. That this deduction is justifiable is evident from the fact that when we find small-pox occurring epidemically in a tolerably well raccinated community, such as that of Scotland, the mortality caused by it among children under five years of age does not attain twenty-five per cent., $t$ or less than one-fourth of all the deaths from small-pox occur at ages under five years, instead of over two-thirds, as in this last epidemic at Rome. In other words, had the population of Rome been even as well vaccinated as that of the larger towns in Scotland, it is probable that the lives of more than two hundred children would have been saved.

Small-pox, however, was unfortunately not the only zymotic disease which raged in the city throughout nearly the whole of 1872 . Diphtheria and croup-combined in the Registrar's reports-were terribly prevalent, and occasioned, in the fifty-two weeks ending December 29th, 571 deaths. Here, too, the proportion of children under five years of age who fell victims was enormous, being 78.8 per cent. of the total deaths from those two complaints. Typhoid fever is entered as the cause of 354 deaths, and pernicious intermittents killed 417 persons. Measles, too, seems to have assumed a destructive type, a 166 deaths are registered from it, only 20 being given as those of persons over five years of age. Scarlatina, on the other hand, was mild, and caused only 25 deaths; nor does any other complaint call for particular notice, except pyæmia, which also figures prominently in the returns. Summing up the deaths from these seven zymotic complaints

\footnotetext{
The returns for January do not discriminate between deaths belonging and not belonging to the community; and there is, consequently, a slight error in the way of excess in the estimated mortality of the year.

+ See Seventeenth Annual Report of the Registrar-General for Scotland, p. 39.
}

-rmall-pox, diphtheria, croup, scarlatina, typhoid fever, measles, and pernicious intermittents - we find that they number 2,270 , or consider. ably more than one-fifth of the total mortality of the year.

The fatality of this class of diseases was, however, by no means uni. formly distributed over the whole twelve months, as may be shown by the accompanying table. Scarlatina has been omitted, on account of its being, fortunately, too insignificant an item in the returns; and owing to the form of the reports, it has been necessary to draw up the table in periods of twelve weeks. The four weeks omitted, from June I th to July I $4^{\text {th, }}$ present no special features, the mortality from all the complaints mentioned being intermediate between the four pre. ceding and the four succeeding weeks.

\begin{tabular}{|c|c|c|c|c|c|}
\hline \multirow{2}{*}{ Year 1872.} & \multicolumn{5}{|c|}{ Deaths. } \\
\hline & Smallpox. & $\begin{array}{l}\text { Diphtheria } \\
\text { and Croup. }\end{array}$ & $\begin{array}{c}\text { Pernicious } \\
\text { Intermittents. }\end{array}$ & $\begin{array}{c}\text { Typhoid } \\
\text { Fever. }\end{array}$ & Measles. \\
\hline $\begin{array}{l}\text { From Jan. I to } \\
\text { March } 24 \\
\text { From March } 25\end{array}$ & 392 & 142 & 52 & 84 & 3 \\
\hline $\begin{array}{l}\text { to June } 16 . . \\
\text { From July }\end{array}$ & 166 & 184 & 39 & 53 & $x_{4}$ \\
\hline $\begin{array}{l}\text { to Oct. } 6 \ldots . \\
\text { From Oct } 7 \text { to }\end{array}$ & 75 & rio & 199 & 105 & 107 \\
\hline Dec. 29 & 71 & 93 & 109 & 84 & 26 \\
\hline
\end{tabular}

This table, though presenting a very high bill of mortality, is so far consolatory that there is a manifest improvement in the last twelve weeks of 1872 -an improvement which we may expect to continue in the present year, as the epidemic of small-pox is now virtually at an end ; no deaths from this cause having been registered in the third week of January, while only seven cases of discrete and semi-confluent variola remained in the small-pox wards when I last visited them; and the other zymotic complaints, too, show a notable diminution in the first four weeks of 1873 .

[To be continued.]

\section{THE ETIOLOGY OF PSORIASIS.}

\section{BY BALMANNO SQUIRE, M.B.Lond.}

As Dr. Myrtle has done me the compliment of commenting on my remarks on the etiology of psoriasis, and has expressed himself as arriving at a somewhat different conclusion -from mine, I beg the privilege of a reply. He does not agree with me that psoriasis was the disease of the "leper as white as snow" of the Bible, and he objects because " the word 'white' does not occur in the original, and is never used by eastern nations as it is by us," although later on he says that " the word 'white' is applied [in the Bible] to the hair and spots of the leper." Now, if I waive this apparent contradiction, and assume with him that the original words stand simply "a leper as snow," am I to understand him as saying that they imply no reference to the whiteness of the leper, and, if so, that they refer to a question of tem. perature, or of purity, or of what ? and (if the word white is never used by eastern nations as it is by us) will he explain in what sense they do use it? The learned individuals who translated the Bible into English, at least, were of opinion that a "leper as snow" (if that be the original) meant a leper as white as snow ; for so they have rendered it.

Dr. Myrtle objects to the identity I have sought to establish between the ancient and the modern disease, that the former, in the instances quoted, "was not disease in the ordinary or natural course, but instances of miraculous interference with healthy skins." But, if it be not profane to think that the constant maintenance of the varied but undeviating laws of nature is a greater miracle than any conceivable devia. tion from them, this argument will not go for much. I am sure of this, that a strong mental emotion is well capable of determining a general eruption of psoriasis ; for such cases have repeatedly come under my notice, and I can conceive no stronger exciting cause of the disease than a solemn curse pronounced by the lips of a person to whom the patient unreservedly imputed supernatural power. To take a case where mental emotion is generally allowed to have a considerable influence, I think I may safely say that most pregnant women would be likely to abort under the circumstances.

Dr. Myrtle then goes on to say that, although there can be no doubt as to psoriasis being hereditary, nevertheless race, so far as he has been

* According to Professor Baccelli, in his pamphlet on La Perniciosita, the maximum number of pernicious intermittents in Rome occurs in the months of July, August, September, and October ; the medium in June, November, December, and January ; and the minimum in February, March, April, and May. 